\title{
A Comparison of Tenocyte Populations from the Core and Periphery of Equine Tendons
}

Cheng Zhang ${ }^{1}$, Rene B. Svensson ${ }^{1}$, Costanza Montagna ${ }^{1}$, Helena Carstensen², Rikke Buhl$^{2}$, Erwin M. Schoof ${ }^{3}$, Michael Kjær ${ }^{1}$, S. Peter Magnusson ${ }^{1,4}$, Ching-Yan Chloé Yeung ${ }^{1 *}$

1. Institute of Sports Medicine Copenhagen, Bispebjerg Hospital and Center for Healthy Aging, University of Copenhagen, Copenhagen, Denmark.

2. Department of Veterinary Clinical Sciences, Faculty of Health and Medical Sciences, University of Copenhagen, Copenhagen, Denmark.

3. Proteomics Core, Technical University of Denmark, Kongens Lyngby, Denmark.

4. Department of Physical and Occupational Therapy, Bispebjerg Hospital, Copenhagen, Denmark.

\section{LIST OF SUPPLEMENTARY FILES}

Supplementary Figure S1. Individual growth curves for tendon cells of each horse.

Supplementary Figure S2. Alcian blue staining by core and periphery SDFT cells.

Supplementary Figure S3. Most abundant proteins detected in horse SDFT cultures.

Supplementary Data 1. Mass spectrometry data of list of proteins and normalized intensities in all samples.

Supplementary Data 2. Customized R code for iDEP analyses.

Supplementary Data 3. Log transformed intensity list with missing values filled in by imputation.

Supplementary Data 4. Heatmap values for proteins ranked by SD.

Supplementary Data 5. Lists of proteins, fold changes and FDR values from DESeq2 analysis. 
Figure S1. Individual growth curves for tendon cells of each horse.

\begin{tabular}{|c|c|c|c|c|c|c|c|}
\hline Horse \# & Group & Age (y) & Sex & Training & Weight (kg) & Races & $\begin{array}{c}\text { Days since last } \\
\text { race }\end{array}$ \\
\hline 3 & Untrained & 7 & $\mathrm{M}$ & None & 460 & 25 & 758 \\
\hline 6 & Untrained & 10 & $\mathrm{~F}$ & None & 490 & 30 & $>1500$ \\
\hline 9 & Untrained & 6 & $\mathrm{~F}$ & None & 528 & 0 & $\mathrm{NA}$ \\
\hline 15 & Untrained & 4 & $\mathrm{M}$ & None & 560 & 0 & $\mathrm{NA}$ \\
\hline 17 & Untrained & 5 & $\mathrm{~F}$ & None & 534 & 0 & NA \\
\hline
\end{tabular}

Horse \#3

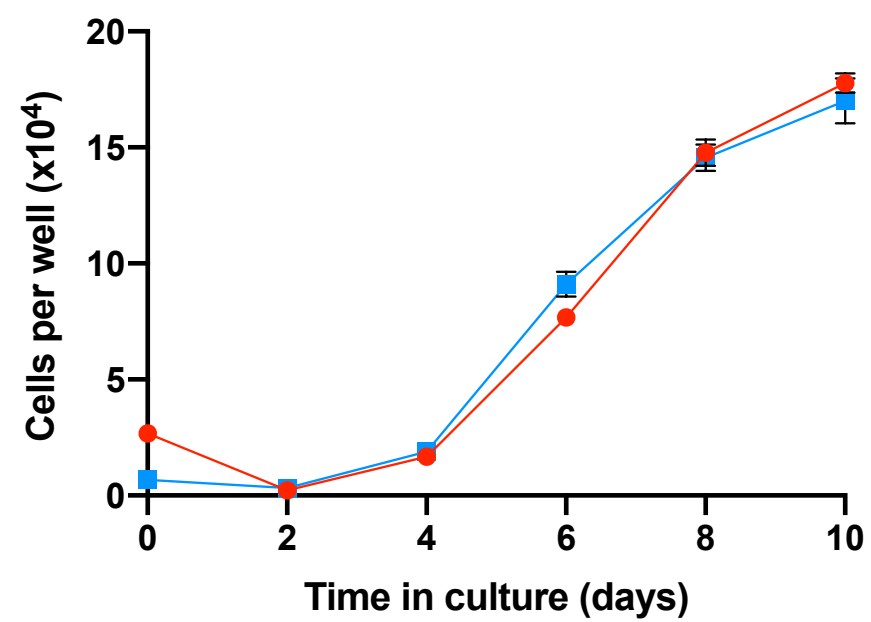

Horse \#9

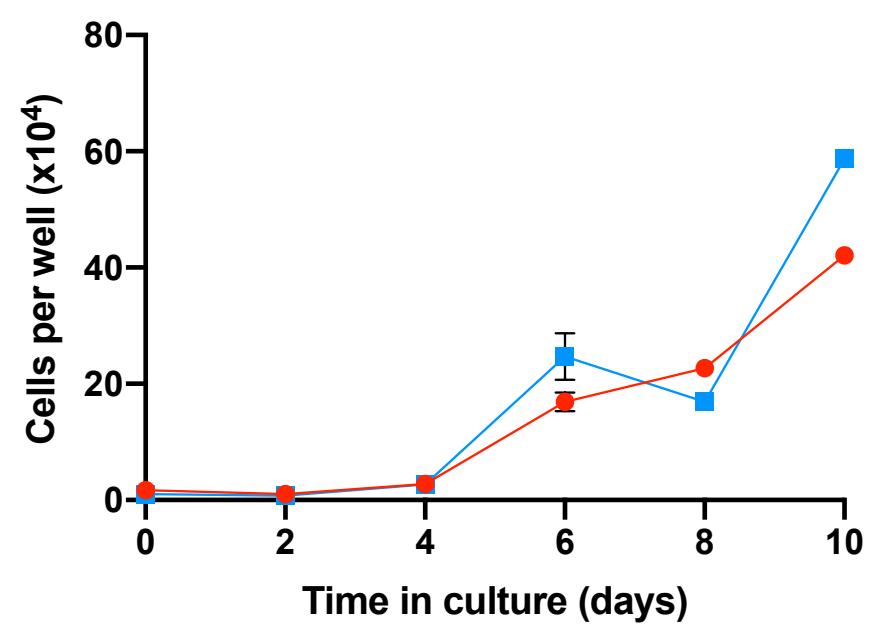

Horse \#17

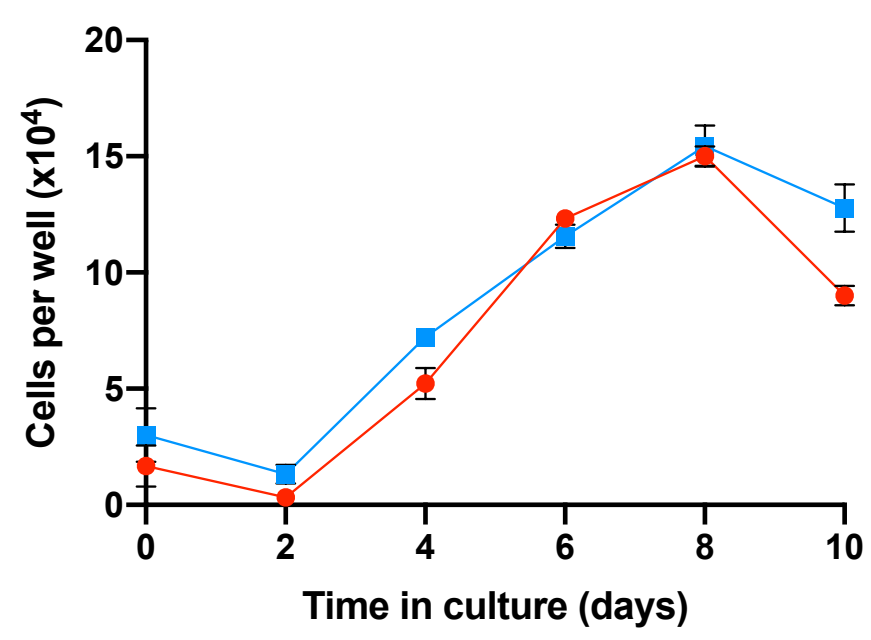

Horse \#6

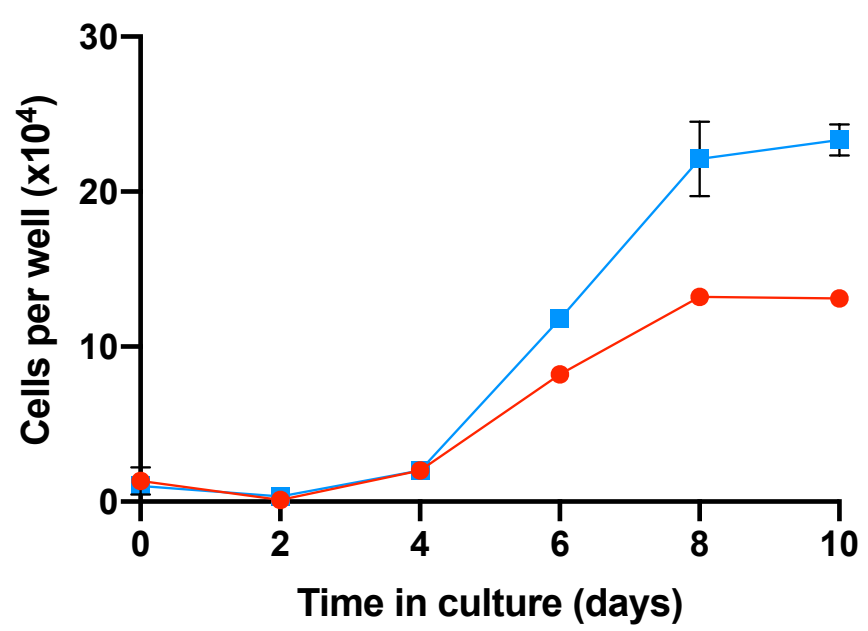

Horse \#15

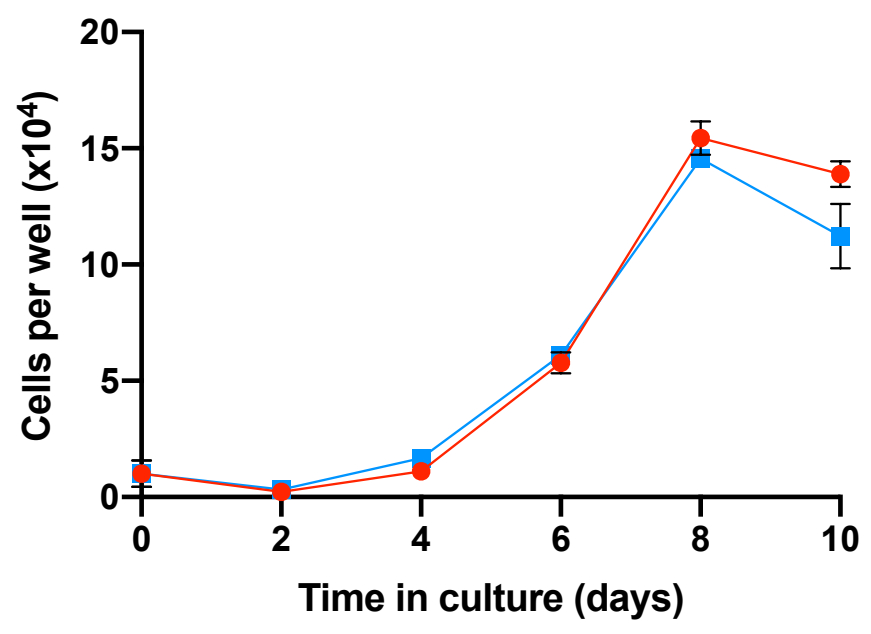

Core

Periphery 
Figure S2. Alcian blue staining by core and periphery SDFT cells.

Core

Periphery

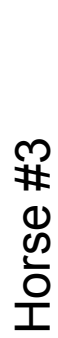

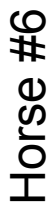

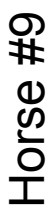
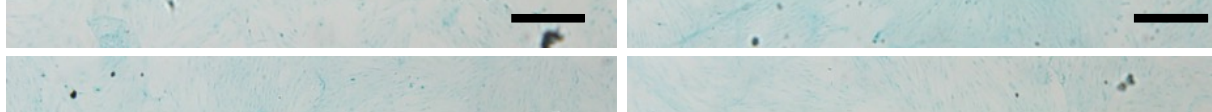

4

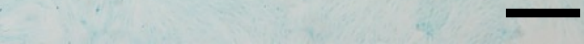

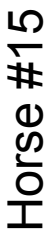
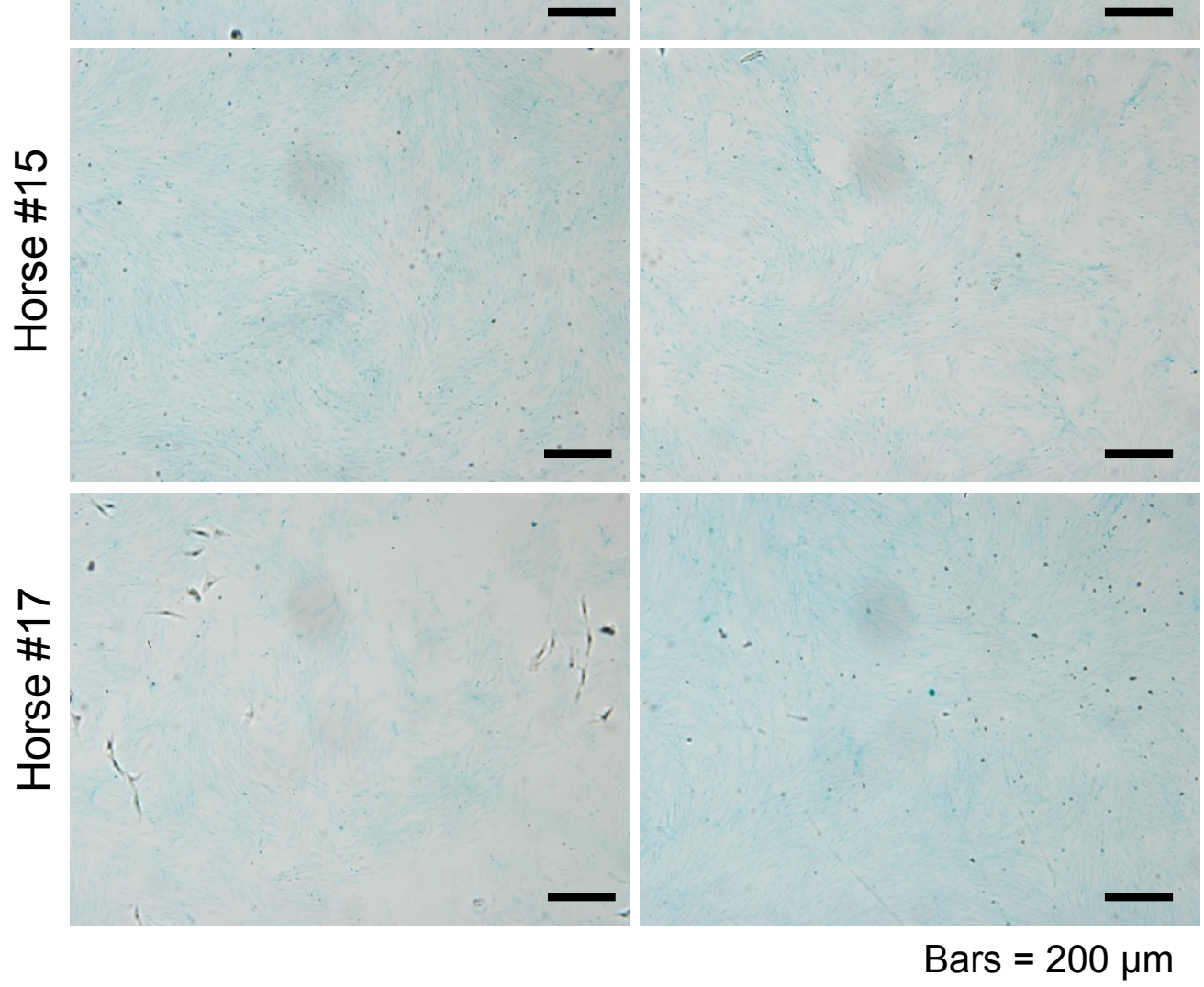
Figure S3. Most abundant proteins detected in horse SDFT cultures.

Top 10 enrichment terms for 100 most abundant proteins detected in horse SDFT cultures:

\begin{tabular}{|c|c|c|c|c|}
\hline & Enrichment term & Enrichment score & \# proteins & p value \\
\hline Annotation Cluster 1 & GO:0030029 actin filament-based process & 14.63 & 17 & $1.12 \mathrm{E}_{-} 12$ \\
\hline Annotation Cluster 2 & GO:0005856 cytoskeleton & 12.14 & 37 & $1.72 \mathrm{E}_{-} 14$ \\
\hline Annotation Cluster 3 & GO:0031988 membrane-bounded vesicle & 10.91 & 21 & $3.05 \mathrm{E}_{-} 10$ \\
\hline Annotation Cluster 4 & GO:0015629 actin cytoskeleton & 10.33 & 18 & $8.96 \mathrm{E}_{-}-13$ \\
\hline Annotation Cluster 5 & GO:0043292 contractile fiber & 6.37 & 12 & $2.74 \mathrm{E}_{-}-10$ \\
\hline Annotation Cluster 6 & GO:0006457 protein folding & 5.75 & 9 & $1.25 \mathrm{E}_{-} 05$ \\
\hline Annotation Cluster 7 & IPR001715:Calponin-like actin-binding & 5.55 & 10 & $9.49 \mathrm{E}_{-}-11$ \\
\hline Annotation Cluster 8 & isopeptide bond & 5.32 & 12 & $2.26 \mathrm{E}_{-} 07$ \\
\hline Annotation Cluster 9 & GO:0043066 negative regulation of apoptosis & 4.22 & 10 & 3. $10 \mathrm{E}_{-}-04$ \\
\hline Annotation Cluster 10 & IPR001464:Annexin & 4.12 & 4 & 4.80E_05 \\
\hline
\end{tabular}

ECM proteins of 1000 most abundant proteins in horse SDFT cultures:

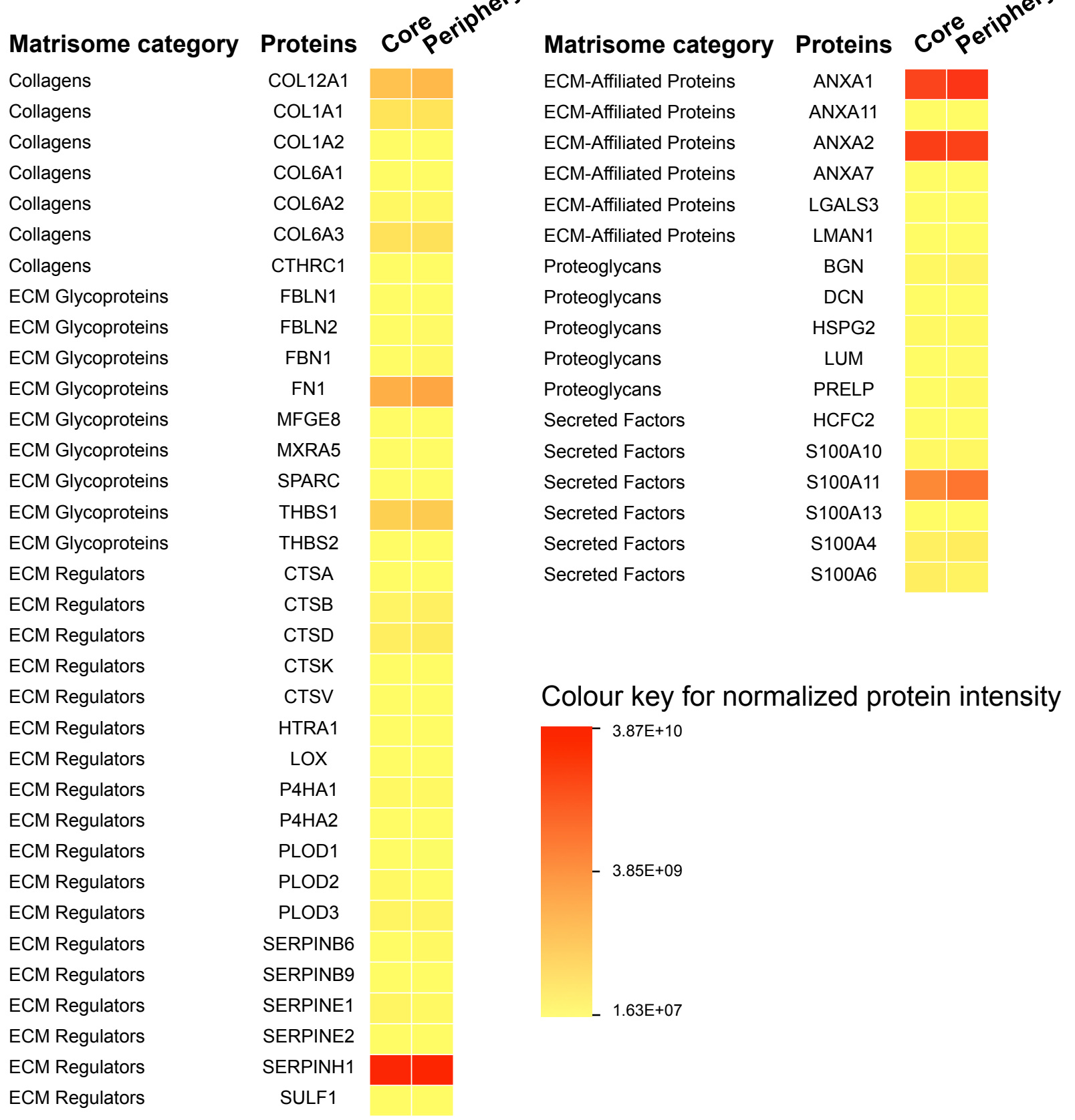

